\title{
Editorial: What Is and What Is Not a Substantial Contribution?
}

Sönke Albers, Editor-in-chief, BuR - Business Research, Kühne Logistics University Hamburg, Germany, E-Mail: editor@business-research.org Caren Sureth, President of German Academic Association of Business Research (VHB); Faculty of Business Administration and Economics, University of Paderborn, Germany, E-mail: csureth@notes.upb.de

There is often a conflict between the interest of the reader in reading articles with as much contribution as possible and the goal of the author to get as many articles out of a certain research project as possible. While in the past smaller contributions seemed to be somewhat more acceptable, editors, especially those of the more ambitious journals, are increasingly requiring more substantial contributions. In particular, these editors are interested in papers that substantially extend our knowledge about any aspect of doing business. Thereby, journals often strived for innovative research, i.e., research on new research questions or innovation in methods, which does not allow the publication of replications. Recently, soliciting replications with non-supporting findings have entered the focus of journals in order to provide a basis of knowledge that can really be trusted. This is also true for BuR - Business Research.

While ethics for publication have always been in place we are currently experiencing some cases that have undermined scientific integrity and honesty in research. It was the dark sides of science, more precisely slicing research into too small pieces (Kirkman and Chen 2011), that alerted our scientific community. When slicing is masked by not citing one's own work it can create misleading impressions of the extent of the article's contribution. E.g., if several empirical articles by the same author used the same dataset then it is not clear whether a variable omission bias might have created artificial results and what the additional contribution over the other studies is. Therefore, BuR calls for it to be revealed whether the study is based on a dataset that has already been used previously by the same author for research on related research questions. If the dataset has been used before, the author has to refer to the other articles or working papers that are using the same dataset. This also relates to submissions by this author that are done in parallel to different journals. Of course, this call for originality and transparency is and has been characteristic not only for empirical work but also correspondingly for analytical and conceptual papers. In the long run it is not in the interest of authors to slice their research because it will not lead to articles with high citation rates but rather reduce the author's reputation. Thus impact and extent of contribution go hand in hand.

If articles are substantially based on other articles by the same author, then readers want to know that, because it also determines the value of the contribution. A special case is given for articles that are written in different languages. If the original article has appeared in German, then we often find that another article written in English did not cite the original article. This is done under the assumption that such a reference does not add value for the English audience. This relates to the similar question of whether German sources should be cited in an English article. We recommend also citing German work. It is an expression of the appreciation of the intellectual property of others. Another special case is given if the author does not cite his own work in German. In this case the intellectual property argument does not hold, but the argument that the editor and the readership should know whether this is something entirely new. In the end, it is always a question of the "truth" of the research activity and the contribution to business research.

BuR evaluates the quality of contributions by reviewers who are renowned experts in their fields. Their valuable work is highly appreciated by the editors. However, this is no guarantee that a reviewer can find all shortcomings. In the end, quality is only assured through a discourse in the scientific community, which is also encouraged in BuR. 
Such a discourse about the value of a contribution can only be achieved if the article is well documented. Otherwise we do not know whether the result can be replicated or generalized. Thus, it would not be clear whether we can really rely on a certain result. In addition, well-documented articles facilitate faster learning, which may not only enable researchers to replicate results, but also inspire them to pursue further research questions. As a consequence, BuR has already called for a careful documentation of model and sample building in an earlier editorial (Albers 2009) and offers a variety of possibilities as an open-access journal to provide additional material publicly to the community. Similar recommendations are given in Albers (2012).

Finally, readers are interested in an unbiased presentation of results. Therefore, all circumstances that could possibly imply conflicts of interest (relevant third-party funding, related consulting activities or positions in relevant organizations) with respect to the paper to be published in BuR must be mentioned. In this respect, BuR follows the principles laid down in the recommendations by the Committee on Publication Ethics (COPE). More generally, BuR as a VHB journal is committed to the Proposals for Safeguarding Good Scientific Practice, Recommendations by the German Research Fund (DFG).

In summary, these diagnostics call for:

1. Articles that have been published as working papers or have been derived from dissertations are welcome if they provide substantial new knowledge that has not been submitted to another journal or published before.
2. Translations of papers that have been published previously in another language (German or other) typically do not provide an incremental contribution to the literature and are not acceptable for BuR.

3. If the article is based on a concept, model or dataset previously used by the same author for a related research question then this author has to disclose this in detail.

4. Furthermore, the research design including the set of assumptions or sample selection must be carefully documented in order to leave no doubt about how premises restrict the generalizability of results and how missing values, hand-collected data, winsorizing, censoring etc. have affected the original dataset. Limitations in the generalizability of results must be described.

5. Previous drafts of the paper that are available as a working paper under a different title should be mentioned in the non-anonymized version that is finally published as a BuR article.

\section{References}

Albers, Sönke (2009): Editorial: Well Documented Articles Achieve More Impact, BuR - Business Research, 2 (1), 8-9.

Albers, Sönke (2012): Optimizable and Implementable Aggregate Response Modeling for Marketing Decision Support, International Journal of Research in Marketing, 29 (2), 111-122.

Committee of Publication Ethics (COPE): Guidelines, http:// publicationethics.org/resources/guidelines (Access date: 2012-1112).

Deutsche Forschungsgemeinschaft (1998): Proposals for Safeguarding Good Scientific Practice, Wiley-VCH: Weinheim.

Kirkman, Bradley L. and Gilad Chen (2011): Maximizing Your Data or Data Slicing? Recommendations for Managing Multiple Submissions from the Same Dataset, Management and Organization Review, 7 (3), 433-446. 